\title{
Inspissated Bile Syndrome with Neonatal Giant Cell Hepatitis ec Congenital Cytomegalovirus Infection: A Case Report
}

\author{
Zuhria Novianty ${ }^{\mathrm{a} *}$, Anna Tjandrawati ${ }^{\mathrm{b}}$ \\ *Corresponding author: zuha.ria@gmail.com \\ ${ }^{a}$ Residency Program, Department of Clinical Pathology, Faculty of Medicine, Padjadjaran University, Dr. Hasan Sadikin Academic \\ General Hospital, Bandung, Indonesia \\ ${ }^{\mathrm{b}}$ Staff in Department of Clinical Pathology, Faculty of Medicine, Padjadjaran University, Dr. Hasan Sadikin Academic General \\ Hospital, Bandung, Indonesia
}

\begin{abstract}
Cytomegalovirus infection is widely spread globally in the form of primary infection, reactivation of infection, or reinfection with a clinical spectrum that varies from asymptomatic to severe symptoms. The infection in pregnant women needs special attention since it can cause congenital infections in infants. Clinical manifestations that often appear in infants with congenital cytomegalovirus infection include biliary atresia. Diagnosis of Cytomegalovirus infection is established based on clinical findings, positive laboratory results of anti-CMV IgM and IgG, and hepatobiliary investigation. Definitive therapy in the form of the Kasai procedure, when performed at an early age, can increase the infants' healing rate and improve their growth and development. In this case report, a baby boy aged 4 months 29 days experienced yellowing of the skin since the age of 2 months accompanied by pale stools. The anti-CMV IgM and IgG showed positive results, and the abdominal ultrasound showed no biliary atresia. However, the hepatobiliary investigation results showed narrowing of the biliary tract lumen, and the liver biopsy results showed neonatal giant cell hepatitis.
\end{abstract}

Keywords: Congenital Cytomegalovirus Infection; Icterus; Inspissated Bile Syndrome

\section{Introduction}

The clinical picture of Cytomegalovirus infection is highly variable and not typical for immunocompetent individuals, including fever, fatigue, muscle aches, cephalalgia, splenomegaly, lymphocytosis with atypical lymphocytes. Meanwhile, this virus can cause pneumonia, gastrointestinal ulcers, hepatitis, encephalitis, or chorioretinitis in immunocompromised individuals. In infants, the symptoms are generally divided into 2, namely congenital infection and perinatal infection. Congenital Cytomegalovirus infection can lead to cytomegalic inclusion disease with various mild symptoms such as petechiae, jaundice due to biliary atresia, and hepatosplenomegaly, or severe symptoms such as microcephaly, intrauterine growth disorders, premature birth, and chorioretinitis. Perinatal Cytomegalovirus infection is usually asymptomatic, but hepatosplenomegaly, neutropenia, lymphocytosis, and thrombocytopenia may occur. ${ }^{1}$

Biliary atresia is a rare disorder characterized by the absence of lumen in the extrahepatic biliary tract causing obstruction to bile flow. Biliary atresia can occur due to congenital anomalies or a prolonged inflammatory process that causes progressive damage to the extrahepatic bile ducts resulting in obstruction of bile flow, accumulation of bile salts, and an increase in direct bilirubin. Biliary atresia requires early detection since surgical treatment with the Kasai procedure is highly successful if performed when the infant is less than 2 months old. Biliary atresia, if not treated with the Kasai procedure, can lead to complications of cirrhosis. Therefore, early detection and action are needed..$^{2,3}$

\section{Case}

A 5-month-old male infant was brought to the Pediatric Polyclinic of Dr. Hasan Sadikin General Hospital (hereinafter referred to as RSHS) for an examination in preparation for surgery. The patient had previously been diagnosed with cholestasis jaundice e.c suspected biliary atresia. The patient was first brought by his parents to the RSHS approximately 3 months earlier (when the infant Was 2 months old) with complaints of yellowing of the skin. The complaint was 
accompanied by an enlarged stomach, pale stools like putty, and brown urine like strong tea. An abdominal CT scan has been performed in the patient showing biliary atresia. Physical examination revealed icteric sclera, and abdominal palpation revealed an enlarged liver approximately 3 fingers below the left costal arch. When he was first brought to the Pediatric Polyclinic of RSHS 3 months earlier (when the infant was 2 months old), this patient was tested for anti-CMV IgG and $\operatorname{IgM}$ with both reactive results.

The patient's Hb level on the first day of hospital admission was $9.5 \mathrm{~g} / \mathrm{dL}$. After receiving a PRC transfusion, the Hb level increased to $13.0 \mathrm{mg} / \mathrm{dL}$. The leukocyte count and differential count examination showed absolute lymphocytosis, absolute monocytosis, and absolute eosinophilia with leukocytosis. The results of blood chemistry examination showed increased liver enzymes, namely serum glutamic oxaloacetic transaminase (SGOT), serum glutamic pyruvic transaminase (SGPT), alkaline phosphatase (ALP), and gamma-glutamyl transferase (GGT), increased total, direct, and indirect bilirubin, and decreased albumin levels.

In addition, the results of ultrasound examination of the abdomen, bile ducts and patent hepatic ducts, as well as the IOC procedure, found that the contrast was still able to pass through the bile ducts and hepatic ducts. The results of the liver biopsy showed no bile plug, but periportal fibrosis was found. The hepatobiliary examination results supported the diagnosis of biliary atresia. The conclusion was that there was a type 1 biliary atresia, which affects the common bile duct with patent gallbladder and hepatic duct/narrowing lumen. Therefore, it was diagnosed as inspissated bile syndrome.

\section{Discussion}

Complaints of jaundice in infants can be a physiological or pathological process. Physiologic jaundice in infants can appear at the age of 2-3 days, reach a peak in 4-5 days, and will gradually disappear until 14 days. ${ }^{4}$ The infant was more than 2 months old when he was first brought to the Pediatric Polyclinic of RSHS, so it can be concluded that the yellow body in this baby is a pathological condition. A complete history and physical examination of other comorbidities and findings on physical examination can help predict the differential diagnosis. In this patient, the accompanying complaints were pale stools like putty and brown urine like strong tea. Besides, based on physical examination, the patient appeared icteric and had hepatomegaly. Based on the history and physical examination of the patient, it could be estimated that the yellowing of the skin was due to obstruction to the flow of metabolic waste from the liver, resulting in the accumulation of bilirubin which causes the patient's skin yellowing. ${ }^{5}$ The accumulation of bilirubin could be either indirect or direct bilirubin. In this patient, it was possibly the accumulation of indirect bilirubin since hepatomegaly was found, but it could also be the accumulation of direct bilirubin since one of the complaints was pale stools like putty.

Bilirubin is the main product of the breakdown of red blood cells by the reticuloendothelial system. Lysed erythrocytes will release heme from hemoglobin in reticuloendothelial cells, and the released heme will be degraded to biliverdin by the enzyme heme oxygenase. Biliverdin is then reduced to bilirubin by the enzyme biliverdin reductase in the cytosol. This bilirubin is referred to as indirect bilirubin (unconjugated bilirubin), which will be bound by albumin and transported through the blood circulation to the liver. Indirect bilirubin in the liver will bind to its receptors on the surface of the hepatocyte cell membrane. Indirect bilirubin will then go to the endoplasmic reticulum, in which conjugation will occur. Indirect bilirubin is metabolized to direct bilirubin with the help of the enzyme glucuronyl transferase. Direct bilirubin is secreted into the biliary system in bile. After being secreted by the liver, bile is stored in the gallbladder until it is stimulated to release the bile into the duodenum. ${ }^{6,7}$

Direct bilirubin is not reabsorbed by the intestinal epithelium but is broken down by the intestinal flora into stercobilin and urobilinogen, which are then excreted in the feces. A small amount of direct bilirubin will be deconjugated by the enzyme B-glucuronidase in the intestinal epithelium, and the indirect bilirubin produced will be reabsorbed into the circulation and back to the liver, which is commonly known as the enterohepatic cycle. ${ }^{6,8}$ Bilirubin metabolism is quite complex and involves various organs. On that ground, infants with jaundice require additional examinations, both laboratory and radiological examinations. Figure 2 . below displays the algorithm for diagnosing infants with jaundice. 


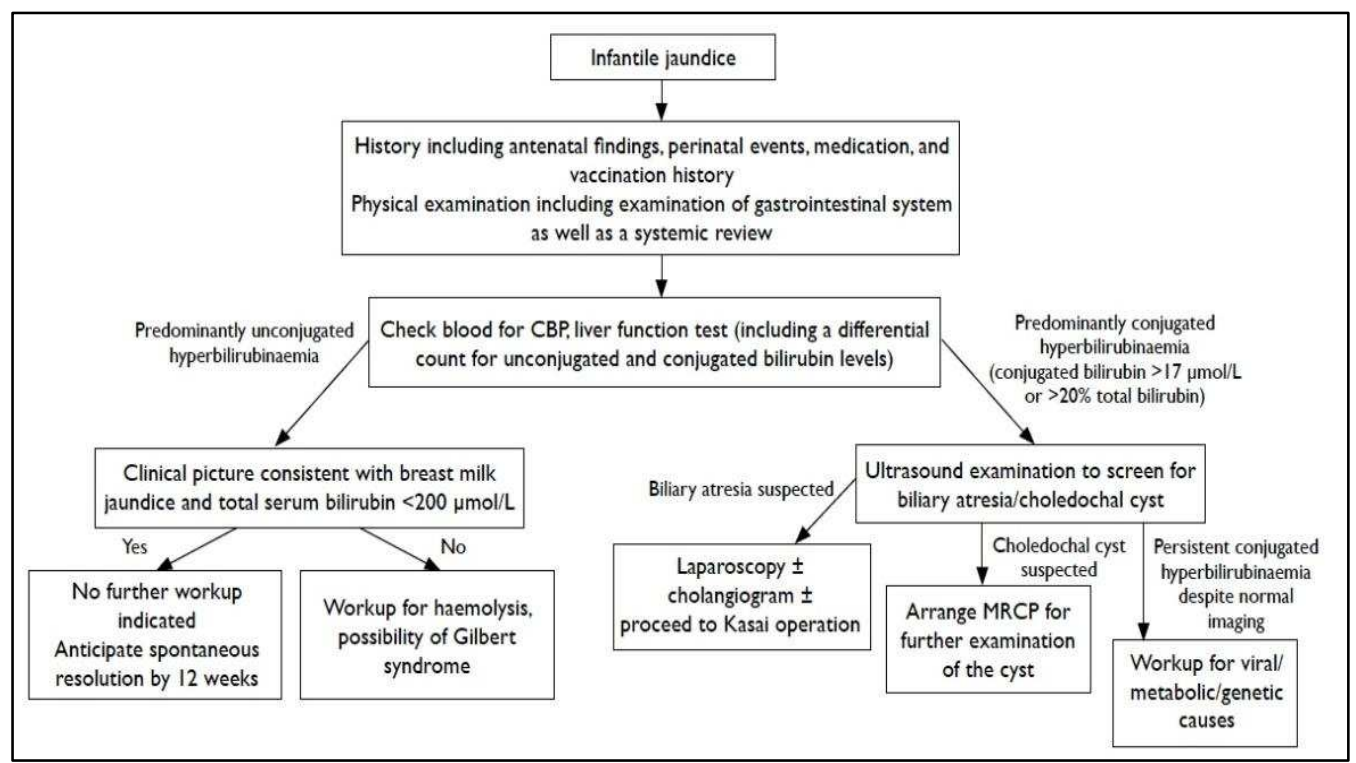

Figure 1. Diagram of Algorithm for Diagnosing Infants with Jaundice

Quoted from: Chee et al ${ }^{9}$

Description: $\mathrm{CBP}=$ Complete Blood Picture

MRCP = Magnetic Resonance Cholangiopancreatography

Based on the above algorithm, the patient's direct bilirubin was $5.935 \mathrm{mg} / \mathrm{dl}$ or $101.49 \mathrm{~mol} / \mathrm{L}$. Therefore, an abdominal ultrasound examination was then performed to identify signs of biliary atresia or choledochal duct cysts. The abdominal ultrasound examination showed an impression of the contractility index value of the gallbladder at the peak of $68 \%$, with no signs of biliary atresia, meaning that the ultrasound examination indicated normal liver and gallbladder. Therefore, the working diagnosis of cholestasis jaundice, e.c suspected biliary atresia, could not be established. The patient's clinical signs indicated jaundice which supported the diagnosis of biliary atresia. For this reason, a hepatobiliary scan was performed, and it demonstrated the presence of biliary atresia. Based on the clinical and hepatobiliary scan results, the patient was planned for an exploratory laparotomy + intraoperative cholangiogram + Kasai procedure.

Biliary atresia in infants can be a congenital disorder or the result of inflammation occurring in a moment after birth, causing damage to the bile ducts. The etiology of biliary atresia has not certainly been discovered. However, it is suspected that it can be caused by viral infections, including viruses belonging to TORCH (Toxoplasma, Rubella, Cytomegalovirus, Herpes simplex virus type 2, and other infections), exposure to toxic substances, and genetic mutations. ${ }^{10,11}$ This disease is characterized by the progressive inflammation of the bile ducts, resulting in extrahepatic obstruction, which can lead to fibrosis and cirrhosis of the liver. The gold standard for the diagnosis of biliary atresia is intraoperative cholangiography (IOC), while the histological examination of tissue biopsy has a fairly good sensitivity of $96.9 \% .^{12}$ The IOC procedure in this patient visualized the biliary tree and showed that the contrast fills the cystic duct, right and left hepatic ducts, common hepatic ducts, common bile ducts, and duodenum.

The results of the biopsy examination in this patient showed no biliary plug, but periportal fibrosis accompanied by neonatal giant cell hepatitis $(\mathrm{NGCH})$ was found. Neonatal giant cell hepatitis is idiopathic hepatitis in neonates characterized by idiopathic cholestasis. Patients usually experience cholestatic jaundice, dark urine, pale stools, and hepatomegaly. The etiology of NGCH includes the infection of Cytomegalovirus, Rubella, Herpes simplex, Coxsackievirus, Echovirus, and Paramyxovirus, among which Cytomegalovirus is the most common. ${ }^{12}$

Cytomegalovirus infection can be a primary infection, reactivation of infection, or reinfection. In immunocompetent individuals, Cytomegalovirus infection is often asymptomatic or mildly symptomatic, and the virus will remain in the host cell in a dormant state. Latent infection can be maintained until certain conditions that allow reactivation, including pregnancy, consumption of immunosuppressant drugs, post-transplant, or transfusion, are met. The reactivation of this viral infection is also mostly asymptomatic. Individuals can also experience reinfection, i.e., an infection that occurs with other Cytomegalovirus strains. ${ }^{13}$ 
The pathogenesis of biliary atresia with viral infection etiology involves the immune system so that each individual may have different responses. This process involves both the innate and adaptive immune systems. Figure 2.6 below displays the immunopathogenesis of biliary atresia.

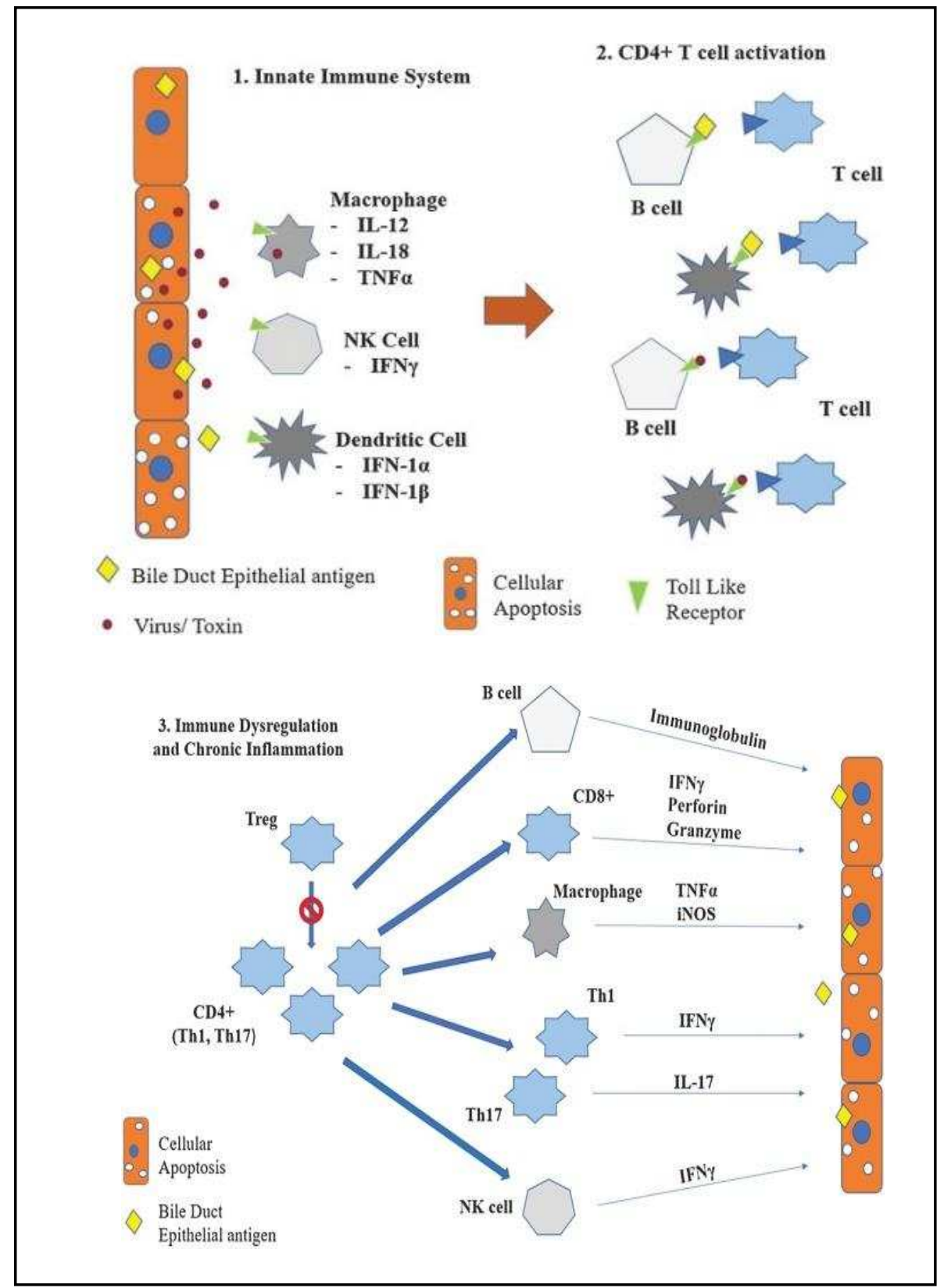

Figure 2. Immunopathogenesis of Biliary Atresia in Cytomegalovirus Infection Quoted from: Averbukh and $\mathrm{Wu}^{14}$

Cytomegalovirus infection that affects the bile duct epithelium will cause the release of pro-inflammatory cytokines, including tumor necrosis factor alpha (TNF- $\alpha$ ), interleukin-1 (IL-1), and interleukin-6 (IL-6). Macrophages, natural killer cells (NK-Cells), neutrophils, and dendritic cells respond to inflammation by migrating to the site of inflammation. These cells have Toll-like receptors (TLRs), and each TLR will recognize viral molecular patterns expressed by infected or necrotic bile duct epithelial cells. The signal regulation failure of TLRs is the basis for the development of chronic inflammation. ${ }^{14}$ 
Macrophages cause epithelial damage by producing TNF- $\alpha$, which induces apoptosis of the bile duct epithelium. Macrophages together with pro-inflammatory cytokines work synergistically to produce an excessive cellular immune response so that inflammation in the bile ducts develops chronically. Natural killer cells in infants are assumed to be immature enough to destroy virus-infected bile duct epithelium. In individuals with normal immune systems, the cellular immune response should be able to inactivate Cytomegalovirus infection, which is an opportunistic virus. However, individuals with impaired immune responses are assumed to experience a decrease in the number of $\mathrm{T}$ cells. These regulatory $\mathrm{T}$ cells serve to prevent the bystander phenomenon, namely damage to epithelial cells in addition to virusinfected bile duct epithelial cells. The decrease in the number of regulatory $\mathrm{T}$ cells causes the bystander phenomenon to be unstoppable and will exacerbate the inflammatory process. ${ }^{14}$

The immune response to Cytomegalovirus infection is the same as that to viral infections in general. Rapid control of acute infections is conducted by the cell-mediated immune system, namely natural killer (NK) cells, CD8+ T cells, and with the help of CD4+ T cells. NK cells are members of non-T to non-B lymphocytes circulating in the blood and tissues and are nonspecific components of the innate immune system. In the early stage of acute infection, in specific immune response, viral antigens are processed by macrophages and presented to CD4+ T ( $\mathrm{T}$ helper) lymphocytes that produce cytokines and trigger the proliferation of sensitized cytotoxic or cytolytic (CD8+) T cells. Activated CD8+ T cells then specifically destroy host cells that express viral antigens binding to major histocompatibility complex (MHC) or human leukocyte antigen (HLA) class I on the cell surface. This immune response is targeted against various antigens such as IE1, IE2, gB, and pp 65 proteins. Specific CD4+ T cells also play an important role in controlling viral infection by releasing interferon- $\gamma(\mathrm{IFN}-\gamma)$ to activate macrophages as phagocytes. ${ }^{15}$

A humoral immune response is formed because antigen fragments that bind to MHC class II molecules are presented by antigen-presenting cells (APC) to CD4+ T lymphocytes. Cytokine production will activate B cells and T cells to proliferate and differentiate into plasma cells that produce antibodies or immunoglobulins. IgM appears first; after that, with somatic mutations in antigen-stimulated B lymphocytes, isotype switching will occur, and other immunoglobulin isotypes are formed such as $\operatorname{IgG}, \operatorname{IgA}, \operatorname{IgE}, \operatorname{IgD}$. The formed antibodies initially have weak antigen-binding power, then affinity maturation occurs for some B cells, resulting in antibodies that can strongly bind antigens. The strength of antibody binding to this antigen is called high affinity and high avidity. ${ }^{15}$

Elevated SGOT and SGPT are often utilized as markers of liver tissue inflammation, while ALP and GGT serve as markers of cholestasis. An increase in indirect bilirubin indicates a disturbance in the conjugation process, while an increase in direct bilirubin indicates a disturbance in the process of excreting hepatic metabolic waste into the duodenum. ${ }^{16,17}$

Albumin is the plasma protein with the highest amount, amounting to 50-60\%. Albumin is synthesized by hepatocyte cells rapidly and will soon be secreted into the bloodstream. In blood circulation, albumin has a half-life of approximately 16-18 hours. Therefore, hepatocyte disorders may cause a decrease in plasma albumin levels. ${ }^{18}$

In this patient, biliary atresia, which causes obstruction to the flow of hepatic metabolic waste, was found, resulting in an increase in ALP, GGT, and direct bilirubin. The results of the biopsy showed neonatal giant cell hepatitis, resulting in an increase in liver enzymes, namely SGOT and SGPT, a decrease in albumin due to impaired synthesis function, and an increase in indirect bilirubin, causing impaired conjugation of bilirubin in hepatocytes. Biliary atresia and NGCH in this patient were the clinical manifestations arising from congenital Cytomegalovirus infection.

After the surgery (Kasai procedure), his bilirubin levels decreased faster than SGOT, SGPT, ALP, and GGT because, in addition to the narrowing of the bile duct lumen, neonatal giant cell hepatitis also occurred. Consequently, after the obstruction to bile flow was resolved through the surgery, the condition of intrahepatic hepatitis and cholestasis has not entirely improved. The patient then received valganciclovir therapy, and on a follow-up, during his visit to the Clinical Polyclinic of RSHS, the patient showed improvement. His yellowing skin gradually disappeared, and his stools were yellow. Besides, hepatomegaly was also not found according to the physical examination performed in the third month after surgery. In addition, laboratory parameters including SGOT, SGPT, ALP, GGT, and albumin gradually improved, probably due to the improving hepatitis condition through valganciclovir antiviral therapy.

The results of the patient's serological examination showed reactive anti-CMV IgG and IgM antibodies. In viral infections, the cellular immune response works approximately 1 week before the humoral immune response. In general, the fetal cellular immune response begins to function properly at the age of 22 weeks. CD4+ T cell activation and differentiation may occur in the fetus, although the ability to produce interferon-gamma (IFN- $\gamma$ ) is still weak. The humoral immune response begins to at 9-11 weeks of gestation, but circulating antibody levels remain low until mid-pregnancy unless high titers of viruses are present and antigen receptors developed on the cell surface. In this situation, antibody levels increase predominantly with IgM. In congenital infection, maternal IgG can cross the placenta into the fetal circulation, 
and $\operatorname{IgM}$ or IgA detected in the umbilical cord blood of neonates indicate that these antibodies were produced by the fetus or the infant itself, which was vertically infected from the mother.

$\mathrm{IgG}$ antibodies are the main antibodies that neutralize and eliminate Cytomegalovirus in the blood circulation. The IgG is an anti-gB antibody (anti-glycoprotein B) that can neutralize and eliminate the most immunogenic antigen of the Cytomegalovirus envelope. An infection is declared new if the serum IgM antibody is positive in the acute phase of the disease or an increase in the serum IgG antibody to more than or equal to 4 times between the acute and convalescent periods. IgM is detectable in the first week of primary infection and becomes undetectable after 1-3 months. Specific IgG appears 1 to 2 weeks after primary infection, reaching its peak 4-8 weeks after primary infection, then declines, but remains detectable at low levels throughout its lifetime. The secondary immune response to reactivation or reinfection gives a different response profile due to the role of memory cells. IgM reappears with lower titers than that in primary infection, and specific $\mathrm{IgG}$ can be detected at the early stage of the disease attack with rapidly rising levels, higher peak, and better antigen-binding power than that in primary infection. ${ }^{15}$

The first sequence of symptoms in this patient was pale stools like putty since the age of 2 weeks, but there was no complaint of yellowing skin at that time. The patient's skin began to turn yellow, and the abdomen was enlarged at the age of 2 months. Based on the order of symptoms and positive anti-CMV IgM results at the age of 2 months, it is potentially a vertical transmission of Cytomegalovirus infection that occurred in the third trimester of pregnancy or direct primary infection in the infant at birth. However, based on the main clinical symptoms in the form of cholestatic jaundice, it is most likely a congenital infection.

The clinical spectrum of congenital Cytomegalovirus infection varies widely, ranging from abortion, hearing loss, cholestasis, petechiae, microcephaly to mental retardation in infants. Based on this fairly broad clinical spectrum, screening for CMV infection in first-trimester pregnant women has become the standard procedure in developed countries. ${ }^{19,20}$ Figure 3. below illustrates the screening algorithm for intrauterine Cytomegalovirus infection.

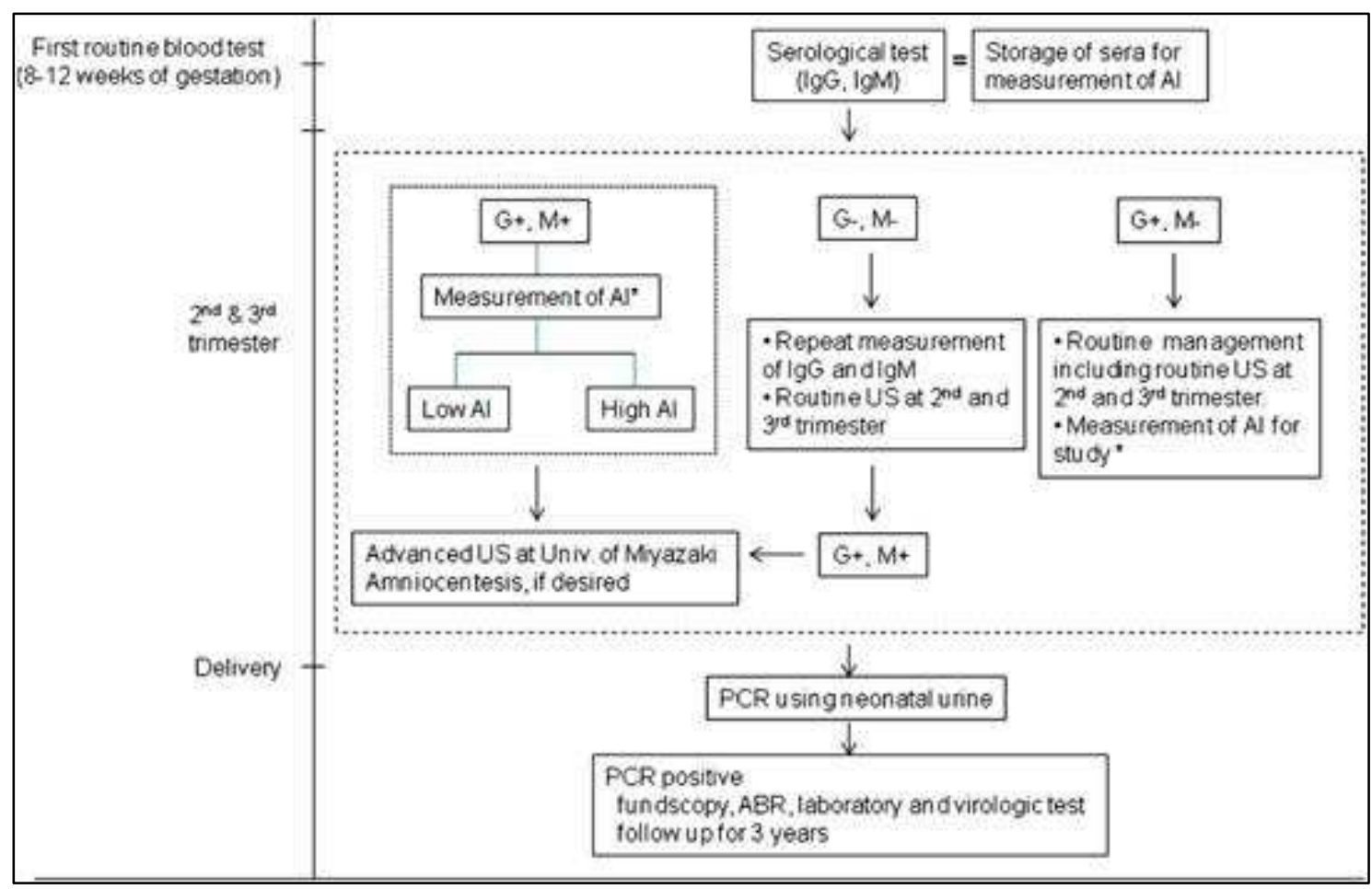

Figure 3. Screening Algorithm for Intrauterine Cytomegalovirus Infection Quoted from: Kaneko et al. ${ }^{21}$

Serum anti-CMV IgM antibodies can be utilized to help assess acute, primary, and congenital infections. Negative anti-CMV IgM antibodies do not mean the patient is entirely recovered because reactivation or reinfection may occur. Besides, positive IgM results do not always indicate acute primary infection since it can also be found in reactivation or 
reinfection. Serial monitoring at intervals of 2-3 weeks is performed to see seroconversion or monitoring for increased antibody levels. The IgG test is performed to detect previously-occurred infections in the past.

If only one $\operatorname{IgG}$ test shows positive results or the $\operatorname{IgG}$ titer reaches the plateau phase with positive $\operatorname{IgM}$, it is impossible to distinguish primary infection from reactivation or reinfection; for that, an avidity test can be performed. IgG produced within 3-5 months after primary infection has low avidity, whereas IgG produced over 3-5 months or years has high avidity.

IgG avidity examination is performed by comparing immunoglobulin levels before and after the addition of certain substances capable of unbinding IgG antibodies against antigens, such as hyperosmolar urea, with the principle that the more mature IgG, the stronger the bonds. In mature IgG, the addition of hyperosmolar urea cannot release the antigenantibody binding, so that the luminescence measurements before and after the addition of hyperosmolar urea would be the same. If the IgG is less than 3-5 months old, then the binding is weak, and with the addition of hyperosmolar urea, the antigen-antibody bond can be released. It causes a difference in luminescence between before and after the addition of hyperosmolar urea. ${ }^{22}$ In certain reagents, avidity measurement was performed based on the ratio of absorbance between antigen-antibody bonds with and without the addition of hyperosmolar urea. The avidity index was calculated by the absorbance formula with the addition of hyperosmolar urea divided by the absorbance without the addition of hyperosmolar urea. An avidity index $<0.60$ indicates low avidity, an avidity index ranges from 0.60 to 0.70 indicates intermediate avidity, and an avidity index $>0.70$ indicates strong avidity.

\section{Conclusions}

Congenital Cytomegalovirus infection has a fairly broad clinical spectrum, with one of the most frequent manifestations of which is biliary atresia. Biliary atresia in infants requires appropriate diagnostic and therapeutic management. Prompt and appropriate action can improve the infant's quality of life and development, while late action can aggravate the disease and cause liver damage.

\section{References}

Congenital Cytomegalovirus Infection: Update on Treatment. BJOG: An International Journal of Obstetrics \& Gynaecology. https://doi.org/10.1111/1471-0528.14836. 2018 2018/01/01;125(1):e1-e11.

Chardot C. Biliary atresia. Orphanet J Rare Dis. 2006;1:28-.

Pratiwi FC, T TW, Prawirohartono EP. Comparison of nutritional status among children with biliary atresia according to age at the time of Kasai procedure. Paediatrica Indonesiana. 2021;59:294-7.

Ullah S, Rahman K, Hedayati M. Hyperbilirubinemia in Neonates: Types, Causes, Clinical Examinations, Preventive Measures and Treatments: A Narrative Review Article. Iran J Public Health. 2016;45(5):558-68.

Ghazy RM, Adawy NM, Khedr MA, Tahoun MM. Biliary atresia recent insight. Egyptian Pediatric Association Gazette. 2018 2018/03/01/;66(1):1-8

Tsai M-T, Tarng D-C. Beyond a Measure of Liver Function-Bilirubin Acts as a Potential Cardiovascular Protector in Chronic Kidney Disease Patients. International journal of molecular sciences. 2018 12/29;20:117.

Feldman AG, Sokol RJ. Neonatal Cholestasis. Neoreviews. 2013;14(2):10.1542/neo.14-2-e63.

Wang J, Guo G, Li A, Cai W-Q, Wang X. Challenges of phototherapy for neonatal hyperbilirubinemia (Review). Experimental and Therapeutic Medicine. 2021 01/20;21.

Young C, Chung P, Wong R, Wong K. Jaundice in infants and children: cause, diagnosis, and management. Hong Kong Medical Journal. 201821 May 2018;24:285-92.

Agawu A, Wehrman A, Pogoriler J, Terry NA, Lin HC. A case report of a challenging diagnosis of biliary atresia in a patient receiving total parenteral nutrition. BMC Pediatr. 2019;19(1):72-.

Chen S-M, Liao Y-Y, Lin C-P. Inspissated bile syndrome: A rare cause of neonatal cholestasis. Pediatrics \& Neonatology. 2020;61(4):449-50.

Situmorang L, Setyoboedi B, Mastutik G, Arief S. Infection of Cytomegalovirus in Cholestasis Infant with Biliary Atresia. 202026 Maret 2020;26:175-81.

Turgeon ML. Immunology \& Serology in Labortory Medicine. Cytomegalovirus. Edisi ke-5. St Louise, Missouri: Elsevier; 2014. hlm. 271-8.

Averbukh LD, Wu GY. Evidence for Viral Induction of Biliary Atresia: A Review. Journal of Clinical Translation Hapetology. 2018;6:410-9.

Suromo LB. Kewaspadaan Terhadap Infeksi Cytomegalovirus serta Keguanaan Deteksi Secara Laboratorik. Pidato Pengukuhan Upacara Penerimaan Jabatan Guru Besar Patologi Klinik; 28 Juli 2007; Semarang: Badan Penerbit Universitas Diponegoro; 2007.

Torbenson M, Hart J, Westerhoff M, Azzam RK, Elgendi A, Mziray-Andrew HC, et al. Neonatal giant cell hepatitis: histological and etiological findings. The American journal of surgical pathology. 2010 Oct;34(10):1498-503.

Poddighe D, Madiyeva A, Talipova D, Umirbekova B. Infantile giant cell hepatitis with autoimmune hemolytic anemia. World J Hepatol. 2021 Apr 27;13(4):411-20.

Gatta A, Verardo A, Bolognesi M. Hypoalbuminemia. Internal and emergency medicine. 2012 Oct;7 Suppl 3:S193-9.

Leruez-Ville M, Sellier Y, Salomon L, Stirnemann J, Jacquemard F, Ville Y. Prediction of Fetal Infection in Cases With Cytomegalovirus Immunoglobulin M in the First Trimester of Pregnancy: A Retrospective Cohort. Clin Infect Dis. 2013 02/07;56. 
Lazzarotto T, Guerra B, Gabrielli L, Lanari M, Landini MP. Update on the prevention, diagnosis and management of cytomegalovirus infection during pregnancy. Clinical Microbiology and Infection. 2011 2011/09/01/;17(9):1285-93.

Kaneko M, Sameshima H, Minematsu T, Kusumoto K, Yamauchi A, Ikenoue T. Maternal IgG avidity, IgM and ultrasound abnormalities: combined method to detect congenital cytomegalovirus infection with sequelae. Journal of perinatology : official journal of the California Perinatal Association. 2013 Nov;33(11):831-5.

Teimouri A, Mohtasebi S, Kazemirad E, Keshavarz H. Role of Toxoplasma gondii IgG Avidity Testing in Discriminating between Acute and Chronic Toxoplasmosis in Pregnancy. Journal of clinical microbiology. 2020 12/31. 